\title{
Effect of Acute Ammonia Intoxication on Cerebral Metabolism in Rats with Portacaval Shunts
}

\author{
Bengt Hindfelt, Fred Plum, and Thomas E. Duffy \\ From the Departments of Neurology and Biochemistry, Cornell University Medical College, \\ New York 10021
}

A B S T RACT Rats were made chronically hyperammonemic by portal-systemic shunting and, $8 \mathrm{wk}$ later, were subjected to acute ammonia intoxication by the intraperitoneal injection of $5.2 \mathrm{mmol} / \mathrm{kg}$ of ammonium acetate. In free-ranging animals, ammonia treatment induced a brief period of precoma (10-15 $\mathrm{min}$ ) that progressed into deep, anesthetic coma lasting for several hours and was associated with a high mortality. In paralyzed, artificially ventilated animals that were lightly anesthetized with nitrous oxide, acute ammonia intoxication caused major disturbances of cerebral carbohydrate, amino acid, and energy metabolism that correlated in time with the change in functional state. At $10 \mathrm{~min}$ after injection (precoma), the concentrations of most glycolytic intermediates were increased, as was the lactate/pyruvate ratio. Citrate declined, despite a twofold rise in pyruvate, suggesting that the conversion of pyruvate to citrate had been impaired. Concentrations of phosphocreatine, and of the putative neurotransmitters, glutamate and aspartate, declined during precoma, but the concentrations of the adenine nucleotides in the cerebral hemispheres, cerebellum, and brain stem remained within normal limits. At $60 \mathrm{~min}$ after injection (coma), ATP declined in all regions of brain; the reduction in total high-energy phosphates was most notable in the brain stem. The findings indicate that cerebral dysfunction in chronic, relapsing ammonia intoxication is not due to primary energy failure. Rather, it is suggested that ammonia-induced depletion of glutamic and aspartic acids, and inhibition of the

This work was presented in part at the 67th Annual Meeting of the American Society for Clinical Investigation, Atlantic City, N. J., 5 May 1975 (1).

Dr. Hindfelt's present address is Department of Neurology, University Hospital, S-221 85 Lund, Sweden. Dr. Duffy is an Established Investigator of the American Heart Association.

Received for publication 6 September 1976 and in revised form 10 November 1976. malate-aspartate hydrogen shuttle are the dominant neurochemical lesions.

\section{INTRODUCTION}

Portal-systemic shunting is an important prerequisite for cerebral dysfunction in chronic liver disease $(2,3)$. The intestinal venous blood circumventing the liver permits potential toxins generated in the gut to enter the systemic circulation, thereby gaining access to the brain. Among the many toxic factors that have been implicated in the pathogenesis of hepatic encephalopathy, ammonia continues to be the leading candidate $(4,5)$. Randomly measured ammonia concentrations in blood and cerebrospinal fluid $(\mathrm{CSF})^{1}$ of patients with hepatic encephalopathy are almost always abnormally increased (6), and it is well documented that the administration of ammonium salts to patients with compromised liver function or extensive portalsystemic shunting may provoke episodic stupor and coma $(7,8)$. Moreover, an elevated concentration of ammonia in brain is a consistent finding in a variety of metabolic encephalopathies including hypoxic hypoxia (9), hypoglycemia (10, 11), hypercapnic acidosis $(12,13)$, cerebral ischemia $(14,15)$, and fluoroacetate poisoning (16), leading several investigators to suggest that the accumulation of ammonia in brain may contribute to the pathogenesis of these disorders $(10,17)$. However, the mechanism by which ammonia causes brain dysfunction is unknown.

The effects of acute ammonia intoxication on cerebral metabolism have been examined experimentally in several laboratories (18-21), but acute hyperammonemia in normal animals may not be relevant to the pathophysiology of human hepatic encephalopathy since the brain in severe liver disease is more susceptible to various kinds of metabolic dis-

${ }^{1}$ Abbreviations used in this paper: CSF, cerebrospinal fluid; PC, portacaval. 
turbances (3). At present, there is no ideal experimental model of chronic hepatic encephalopathy.

Animals with a portacaval anastomosis allow one important aspect of liver disease to be investigated, i.e., the cerebral complications of chronic portalsystemic shunting. Accordingly, we studied the effects of an acute ammonia challenge on cerebral carbohydrate, amino acid, and energy metabolism in rats that had been subjected to portal-systemic shunting for $8 \mathrm{wk}$. The experiments mimic the situation in patients with liver by-pass who suffer from superimposed ammonia intoxication owing either to acute gastrointestinal bleeding or a sudden increase in protein intake. The findings indicate that, similar to events in man, degrees of ammonia loading that produce mild cerebral dysfunction in normal animals induce behavioral encephalopathy and a high morbidity in portacaval animals. Concurrently, the brain undergoes three major neurochemical abnormalities: the conversion of pyruvate to citrate is impaired; the putative neurotransmitters, glutamate and aspartate, are depleted; and high energy phosphates decline, presumably secondary to inhibition of the malate-aspartate hydrogen shuttle.

\section{METHODS}

Operative techniques. Adult male Wistar rats, weighing 250-350 g, were anesthetized with ether, and an end-to-side portacaval (PC) anastomosis was constructed according to the procedure described by Lee and Fisher (22). Shamoperated rats, matched for weight, were similarly anesthetized and a laparotomy was performed; the inferior vena cava and portal vein were isolated, simultaneously occluded for $20 \mathrm{~min}$ and then released, but no shunt was constructed. No antibiotics were administered. Postoperatively, all animals were housed in a germ-free, laminar air-flow room and fed ordinary rat pellets and water ad lib. During the lst-postoperative wk, shunted animals lost weight (approximately $8-10 \%$ ), but thereafter increased in body weight over the ensuing 7 to $15 \mathrm{wk}$ period. At the time of sacrifice, there were no marked differences in weight gain between the shunted and sham-operated groups, a finding in agreement with observations of Holmin and Siesjö (23). The overall mortality in the shunted series was less than $10 \%$.

Experimental design. All metabolic studies were carried out on paralyzed, artificially ventilated animals that were lightly anesthetized with nitrous oxide. The rats were briefly anesthetized with ether, tracheotomized, and mechanically ventilated with oxygen-nitrous oxide (25-75\%) by a Harvard respirator. (Harvard Apparatus Co. Inc., Millis, Mass.) Paralysis was achieved with $d$-tubocurarine chloride $(2 \mathrm{mg} / \mathrm{kg}, \mathrm{IM})$. The tail artery was cannulated for continuous blood pressure monitoring and for anaerobic sampling of blood. Rectal temperature was maintained at $37.0 \pm 0.5^{\circ} \mathrm{C}$ by a thermistor-controlled heating lamp. The skull and the atlanto-occipital membrane were exposed through a midline incision, and a small plastic funnel was sutured over the exposed calvarium for subsequent freezing of the brain in situ.

When the animals had achieved a normocapnic respiratory steady state $\left(\mathrm{P}_{\mathrm{a}} \mathrm{O}_{2}>80 \mathrm{~mm} \mathrm{Hg} ; \mathrm{P}_{\mathrm{a}} \mathrm{CO}_{2} 38.5 \pm 1.2 \mathrm{~mm} \mathrm{Hg}\right.$;
$\mathrm{pH}_{\mathrm{a}}$ 7.39-7.41) and were normotensive (mean arterial blood pressure $>100 \mathrm{~mm} \mathrm{Hg}$ ), some sham-operated controls and animals with PC shunts of 3,8 , or 16 wk duration were sacrificed by pouring liquid nitrogen into the cranial funnel to freeze the brain in situ. Other animals that had been shunted for $8 \mathrm{wk}$ were injected intraperitoneally with either ammonium acetate $(5.2 \mathrm{mmol} / \mathrm{kg}$ dissolved in physiological saline) or an equimolar amount of sodium acetate. Experimental animals were sacrificed at 10 and $60 \mathrm{~min}$ after ammonium acetate injection by freezing their brains in situ with liquid nitrogen; PC-shunted control rats were frozen $60 \mathrm{~min}$ after the injection of sodium acetate. Immediately before sacrifice, samples of arterial blood and cisternal CSF were withdrawn for chemical analysis and frozen in liquid nitrogen. Frozen specimens of brain, blood, and CSF were stored at $-80^{\circ} \mathrm{C}$ until extracted and analyzed.

Spontaneous behavior after the intraperitoneal injection of ammonium or sodium acetate $(5.2 \mathrm{mmol} / \mathrm{kg})$ was evaluated in 17 unparalyzed, unanesthetized rats that had PC shunts of $8 \mathrm{wk}$ duration. No physiological monitoring was performed on this group.

Extractions and analytical procedures. The frozen brains were dissected in a $-20^{\circ} \mathrm{C}$ room under intermittent irrigation with liquid nitrogen. Three major regions were taken for analysis: cerebral hemispheres (entire forebrain anterior to a mid-collicular cut excluding the olfactory lobes), cerebellum, and brain stem (portion extending from the caudal medulla oblongata to the inferior colliculus). The tissues were extracted by the procedure of Nelson et al. (24) as modified by Folbergrová et al. (12). The frozen specimens $(100-200 \mathrm{mg})$ were weighed at $-20^{\circ} \mathrm{C}$ and transferred to homogenization tubes containing 2 vol of $0.1 \mathrm{~N} \mathrm{HCl}$ in methanol. The mixtures were homogenized at $-20^{\circ} \mathrm{C}$, then warmed to $0^{\circ} \mathrm{C}$ and diluted with 5 vol of ice-cold $0.3 \mathrm{M}$ $\mathrm{HClO}_{4}$ containing $1.0 \mathrm{mM}$ EDTA. The mixtures were rehomogenized and centrifuged $(8,000 \mathrm{~g})$ for $30 \mathrm{~min}$ at $0^{\circ} \mathrm{C}$. The supernatant fluids were removed and the tissue pellets were again suspended in $0.5 \mathrm{ml}$ of $0.3 \mathrm{M} \mathrm{HClO}_{4}$ containing $1.0 \mathrm{mM}$ EDTA, and homogenized at $0^{\circ} \mathrm{C}$. After centrifugation, the supernatant fluids from both extraction steps were pooled and neutralized with a solution of $1.5 \mathrm{M} \mathrm{KOH}$, $0.4 \mathrm{M}$ imidazole (low-fluorescence grade), and $0.3 \mathrm{M} \mathrm{KCl}$ to a final $\mathrm{pH}$ of 6.8-7.0. Precipitated $\mathrm{KClO}_{4}$ was removed by centrifugation, and the neutralized extracts were stored at $-80^{\circ} \mathrm{C}$ until analyzed.

Frozen samples (about $100 \mathrm{mg}$ ) of whole blood and CSF were deproteinized with $5 \mathrm{vol}$ of $0.6 \mathrm{M} \mathrm{HClO}_{4}$ at $0^{\circ} \mathrm{C}$. Neutralized extracts of these samples were prepared and stored as described for the brain specimens.

Methods of assay. Substrates were measured fluorometrically with $1 \mathrm{ml}$ of reagent that contained a pyridine nucleotide and appropriate enzymes and cofactors. Ammonia was determined with glutamic dehydrogenase according to the procedure of Folbergrová et al. (25); lactate was determined with lactic dehydrogenase as described by Vannucci and Duffy (26). Aspartate and alanine were measured according to the conditions reported by Duffy et al. (27). Glutamine was assayed as glutamate after incubation $\left(37^{\circ} \mathrm{C}\right)$ of 4.1 $\mu \mathrm{l}$ of extract (equivalent to $0.3 \mathrm{mg}$ of brain) with $150 \mu \mathrm{l}$ of $100 \mathrm{mM}$ citrate-phosphate buffer ( $\mathrm{pH} 4.5$ ) containing 20 $\mu \mathrm{g} / \mathrm{ml}$ of Escherichia coli glutaminase; other conditions were as described by Vergara et al. (18). All other substances, except for asparagine and $\gamma$-aminobutyrate, were determined according to the methods of Lowry and Passonneau (29).

For asparagine, a two-step fluorometric modification of the method of Bergmeyer et al. (30) was adopted. In the first step, endogenous tissue aspartate was removed by incubation 


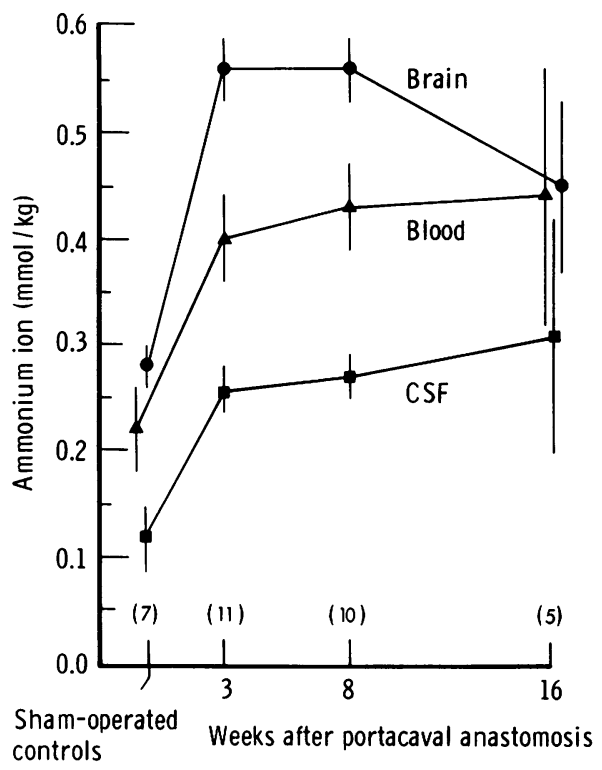

FIgURE 1 Concentrations of ammonium ion in cerebral hemispheres (brain), arterial blood, and cisternal CSF of rats after the construction of a PC anastomosis. Points denote mean values for the numbers of animals shown in parentheses. Vertical lines represent \pm 1 SEM. Sham-operated controls were studied 8 wk after sham surgery.

of $20 \mu \mathrm{l}$ of extract (equivalent to $1.5 \mathrm{mg}$ of brain) with $125 \mu \mathrm{l}$ of a reagent consisting of $100 \mathrm{mM}$ Tris $-\mathrm{HCl}$ (pH 8.2), $3.0 \mathrm{mM} \alpha$-ketoglutarate, $0.075 \mathrm{mM}$ NADH, $0.005 \%$ (wt/vol) bovine serum albumin, $10 \mu \mathrm{g} / \mathrm{ml}$ of heart malic dehydrogenase, and $22 \mu \mathrm{g} / \mathrm{ml}$ of heart glutamic-oxalacetic aminotransferase. After $10 \mathrm{~min}$ at room temperature, the mixtures were acidified with $3.16 \mu \mathrm{l}$ of $6 \mathrm{~N} \mathrm{HCl}$ and incubated $\left(37^{\circ} \mathrm{C}\right)$ an additional $10 \mathrm{~min}$ to destroy residual NADH. (Asparagine is stable under these conditions; even in $1 \mathrm{~N}$ $\mathrm{HCl}$ at $37^{\circ} \mathrm{C}$, the rate of hydrolysis of asparagine does not exceed $1 \% / \mathrm{h}$ [31].) In the second step, the acid mixtures were diluted with $1.0 \mathrm{ml}$ of a reagent consisting of $50 \mathrm{mM}$ Tris- $\mathrm{HCl}$ ( $\mathrm{pH} 8.2$ ), $0.75 \mu \mathrm{M} \mathrm{NADH}, 0.1 \mathrm{mM} \alpha$-ketoglutarate, and $9 \mu \mathrm{g} / \mathrm{ml}$ of malic dehydrogenase. After reading the fluorescence, $0.1 \mu \mathrm{g}$ of $E$. coli asparaginase was added and the decrease in fluorescence was measured when the reaction was completed (30 $\mathrm{min})$.

$\gamma$-Aminobutyrate (GABA) was measured with a partially purified, cell-free preparation from Pseudomonas fluorescens that contained both $\gamma$-aminobutyrate aminotransferase and NADP-dependent succinic semialdehyde dehydrogenase activities (32). The reagent consisted of $100 \mathrm{mM}$ sodium pyrophosphate buffer (pH 8.4), $0.04 \mathrm{mM}$ NADP, $0.1 \mathrm{mM} \alpha$-ketoglutarate, and $1 \mathrm{mM}$ 2-mercaptoethanol. Extract equivalent to $2 \mathrm{mg}$ of brain was added and the fluorescence change induced by the addition of $0.13 \mathrm{mg}$ of Gabase (in $50 \%$ glycerol, Sigma Chemical Co., St. Louis, Mo.) was determined.

Reagents. Enzymes were obtained from Boehringer Mannheim Corp. (New York), except for beef heart lactic dehydrogenase (Worthington Biochemical Corp., Freehold, N. J.) and Gabase (Sigma Chemical Co.). Substrates used as standards were purchased from Sigma Chemical Co. in the highest purity available.

\section{RESULTS}

Ammonium ion and free amino acid levels after $P C$-shunting. Sustained hyperammonemia is a wellknown effect of portal-systemic shunting in man (8) and animals $(33,34)$. PC shunting in rats caused a 2-2.5-fold increase in the ammonia content of brain, blood, and cisternal CSF that persisted for $16 \mathrm{wk}$ (Fig. 1). Concentrations of ammonia were always highest in brain, the single exception being at $16 \mathrm{wk}$ when the brain and blood values were similar. Concentrations of ammonia were lowest in CSF and averaged approximately $65 \%$ of the blood ammonia level.

PC shunting was also associated with changes in the concentrations of several amino acids of brain (Table 1),

TABLE I

Free Amino Acid Concentrations in Rat Forebrain at Intervals after PC Anastomosis

\begin{tabular}{lcccc}
\hline \multirow{2}{*}{ Substance } & Control (7) & $3 \mathrm{wk}(11)$ & $8 \mathrm{wk}(10)$ & $16 \mathrm{wk}(5)$ \\
\cline { 3 - 5 } Glutamate & $10.66 \pm 0.28$ & $9.64 \pm 0.26^{*}$ & $9.07 \pm 0.38^{*}$ & $9.81 \pm 0.24^{*}$ \\
Glutamine & $5.36 \pm 0.67$ & $14.1 \pm 0.8 \ddagger$ & $14.0 \pm 1.0 \ddagger$ & $11.0 \pm 1.0 \ddagger$ \\
Aspartate & $2.68 \pm 0.11$ & $2.63 \pm 0.10$ & $2.76 \pm 0.07$ & $3.11 \pm 0.11^{*}$ \\
Asparagine & $0.093 \pm 0.002$ & $0.118 \pm 0.005^{*}$ & $0.109 \pm 0.004$ & $0.104 \pm 0.004$ \\
Alanine & $0.48 \pm 0.05$ & $0.50 \pm 0.03$ & $0.47 \pm 0.03$ & $0.49 \pm 0.04$ \\
$\gamma$-Aminobutyrate & $1.65 \pm 0.13$ & $1.86 \pm 0.06$ & $1.75 \pm 0.04$ & $1.66 \pm 0.18$ \\
\hline
\end{tabular}

Values, expressed as millimoles/kilogram wet weight, are the means $\pm \mathrm{SEM}$ for the number of animals shown in parentheses.

* Different from control with $P<0.01$.

\# Different from control with $P<0.001$. 
TABLE II

Concentrations of Ammonium Ion in Three Regions of Brain, in Arterial Blood, and in Cisternal CSF of Rats with PC Shunts. Effect of Ammonium Acetate Injection

\begin{tabular}{|c|c|c|c|}
\hline \multirow[b]{2}{*}{ Sample } & \multirow{2}{*}{$\frac{\text { Injected with sodium acetate }}{+60 \mathrm{~min}}$} & \multicolumn{2}{|c|}{ Injected with ammonium acetate } \\
\hline & & $+10 \min$ & $+60 \min$ \\
\hline Cerebral hemispheres & $0.49 \pm 0.05$ & $2.52 \pm 0.31^{*}$ & $3.40 \pm 0.42 *$ \\
\hline Cerebellum & $0.48 \pm 0.06$ & $2.60 \pm 0.24^{*}$ & $4.82 \pm 0.95 * t$ \\
\hline Brain stem & $0.39 \pm 0.02$ & $2.96 \pm 0.48^{*}$ & $3.83 \pm 0.37 *$ \\
\hline Arterial blood & $0.41 \pm 0.06$ & $1.45 \pm 0.32 *$ & $1.00 \pm 0.12^{*}$ \\
\hline CSF & $0.23 \pm 0.03$ & $1.24 \pm 0.22 *$ & $1.48 \pm 0.30^{*}$ \\
\hline
\end{tabular}

Rats with PC shunts of $8 \mathrm{wk}$ duration were injected intraperitoneally with either sodium acetate or ammonium acetate $(5.2 \mathrm{mmol} / \mathrm{kg})$, and were sacrificed 10 or $60 \mathrm{~min}$ later. Values, expressed as millimoles/kilogram wet weight (brain) or millimoles/liter (blood and CSF), are the means \pm SEM for 8-10 animals.

* Different from sodium acetate-injected with $P<0.001$.

$\$$ Significantly higher than the ammonium acetate +10 min value with $P<0.05$.

notably those involved in cerebral ammonia metabolism. Thus, glutamate declined and glutamine more than doubled by $3 \mathrm{wk}$ after shunting, and these differences persisted for $16 \mathrm{wk}$. Despite the decrease in glutamate, no changes in brain $\gamma$-aminobutyrate could be demonstrated. Since the biochemical abnormalities of elevated ammonia and glutamine and decreased glutamate in brain were maximal at $8 \mathrm{wk}$ after shunting, and because a comparable length of time (i.e., more than $5 \mathrm{wk}$ ) is required to demonstrate Alzheimer's glial changes in the brains of PC rats $(35,36)$, animals shunted for $8 \mathrm{wk}$ were chosen for subsequent studies of the behavioral and metabolic effects of an acute ammonia challenge.

Behavioral responses to ammonia loading. The intraperitoneal injection of a small dose of ammonium acetate $(5.2 \mathrm{mmol} / \mathrm{kg})$ into 10 rats with PC shunts of 8 wk duration produced in all animals toxic manifestations (decreased locomotion, multifocal myoclonus) within $2-5 \mathrm{~min}$. After $10 \mathrm{~min}$, the animals became drowsy although responsive to noxious stimuli (precomatose state), and by 15-30 min they lapsed into a deep, anesthetic coma that lasted from 2 to $5 \mathrm{~h}$. Electroencephalograms obtained from three animals showed progressive slowing to a predominant frequency of $4-5 \mathrm{~Hz}$ accompanied by triphasic waves similar to those observed in human beings with hepatic coma. 4 of the 10 rats died, but none within $1 \mathrm{~h}$ after injection. It is noteworthy that no animal exhibited the tonic-clonic convulsions that characterize acute ammonia intoxication in previously unexposed animals (37). Thus, the behavioral response of PC rats to ammonia loading could be separated into two welldefined stages of cerebral dysfunction, i.e., precoma and coma. Therefore, these functional states were correlated with the metabolic status of the brain over the same time period ( 10 and $60 \mathrm{~min}$ after ammonium acetate injection; see below).

The toxic manifestations observed in sham-operated rats injected with ammonium acetate $(5.2 \mathrm{mmol} / \mathrm{kg}$, i.p.) were more benign and transient than those observed in rats with PC shunts. The initial reactions were similar, i.e., drowsiness and myoclonus within minutes after injection, but only four out of seven animals became unresponsive and all four of these regained consciousness after $45 \mathrm{~min}$. All survived. Rats with PC shunts that were injected with an equimolar amount of sodium acetate showed no toxic symptoms.

Concentrations of ammonium ion in brain, blood, and CSF. The concentrations of ammonium ion in arterial blood, cisternal CSF, and three brain regions of rats with PC shunts for 8 wk are given in Table II. In the shunted control group (injected with sodium acetate), the concentrations of ammonium ion in the cerebral and cerebellar hemispheres were similar, whereas somewhat lower concentrations $(-20 \% ; P$ $<0.05$ ) were observed in the brain stem. A similar regional variation in brain ammonia content has also been observed in normal rats (38). Ammonia intoxication was associated with a marked rise in the arterial blood ammonia level at $10 \mathrm{~min}(3.5$-fold), whereas ammonia concentrations in brain and CSF increased even more ( $>$ fivefold); the relative increase was most striking in the brain stem. At $60 \mathrm{~min}$ after injection, concentrations of ammonia tended to be further increased in all regions of brain (although differences from the $10-\mathrm{min}$ values were significant only in cerebellum) despite the fact that blood ammonia 
TABLE III

Concentrations of Adenine Nucleotides, Phosphocreatine, Creatine, and Inorganic Phosphate in Cerebral Hemispheres of Rats with PC Shunts. Effect of Ammonium Acetate Injection

\begin{tabular}{lcccc}
\hline & Injected with sodium acetate & & \multicolumn{2}{c}{ Injected with ammoniun acetate } \\
\cline { 2 - 4 } \cline { 5 - 6 } \multicolumn{1}{c}{ Substance } & $+60 \mathrm{~min}$ & & $+10 \mathrm{~min}$ & $+60 \mathrm{~min}$ \\
\hline ATP & $2.65 \pm 0.05$ & & $2.63 \pm 0.05$ & $2.40 \pm 0.07^{*}$ \\
ADP & $0.26 \pm 0.01$ & & $0.23 \pm 0.01$ & $0.27 \pm 0.02$ \\
AMP & $0.036 \pm 0.007$ & & $0.050 \pm 0.015$ & $0.052 \pm 0.008^{*}$ \\
Phosphocreatine & $5.02 \pm 0.15$ & & $4.10 \pm 0.22^{*}$ & $3.98 \pm 0.18^{*}$ \\
Creatine & $4.96 \pm 0.19$ & & $5.97 \pm 0.22^{*}$ & $5.83 \pm 0.29^{*}$ \\
Inorganic phosphate & $2.33 \pm 0.11$ & & $2.96 \pm 0.27^{*}$ & $3.28 \pm 0.47^{*}$ \\
ATP/ADP & $11.9 \pm 1.2$ & & $11.6 \pm 0.7$ & $8.5 \pm 0.5^{*}$ \\
\hline
\end{tabular}

The animals were the same as those recorded in Table II. Values, expressed as millimoles/kilogram wet weight, are the means \pm SEM for 8-10 animals.

* Different from sodium acetate-injected with $P<0.05$.

levels were no higher at $60 \mathrm{~min}$ than at $10 \mathrm{~min}$ and may even have been decreased $(P<0.1)$.

Cerebral energy balance. The injection of ammonium acetate into PC animals produced a pattern of change in the concentrations of high-energy phosphates and their degradation products that was similar in all regions of brain (Tables III-V). After $10 \mathrm{~min}$, phosphocreatine was uniformly depressed, and there were corresponding increases in the concentrations of creatine and inorganic phosphate. Concentrations of ATP, ADP, and AMP remained unchanged, as did the
ATP/ADP ratios. After $1 \mathrm{~h}$, the situation was different. Phosphocreatine was further decreased and inorganic phosphate was further increased, but there were now substantial reductions in the concentration of ATP in all regions. The changes in ATP were partly realized as increased AMP. Because the concentrations of ADP tended to be higher in all regions after $60 \mathrm{~min}$, the resultant ATP/ADP ratios declined $(P$ $<0.01)$. These alterations in energy state were most pronounced in the brain stem, a finding consistent with the observation by Schenker et al. (19) that

TABLE IV

Concentrations of Adenine Nucleotides, Phosphocreatine, Creatine, and Inorganic Phosphate in Cerebellum of Rats with PC shunts. Effect of Ammonium Acetate Injection

\begin{tabular}{lcccc}
\hline & \multicolumn{2}{c}{ Injected with sodium acetate } & & \multicolumn{2}{c}{ Injected with ammonium acetate } \\
\cline { 2 - 3 } \cline { 5 - 5 } \multicolumn{1}{c}{ Substance } & $+60 \mathrm{~min}$ & & $+10 \mathrm{~min}$ & $+60 \mathrm{~min}$ \\
\hline ATP & $2.58 \pm 0.10$ & & $2.49 \pm 0.10$ & $2.23 \pm 0.08^{*}$ \\
ADP & $0.23 \pm 0.02$ & & $0.24 \pm 0.01$ & $0.26 \pm 0.01$ \\
AMP & $0.037 \pm 0.011$ & & $0.042 \pm 0.007$ & $0.048 \pm 0.010^{*}$ \\
Phosphocreatine & $6.15 \pm 0.22$ & & $5.26 \pm 0.23^{*}$ & $3.96 \pm 0.41^{*}$ \\
Creatine & $6.63 \pm 0.46$ & & $7.36 \pm 0.28^{*}$ & $7.82 \pm 0.54^{*}$ \\
Inorganic phosphate & $2.90 \pm 0.24$ & & $3.34 \pm 0.20^{*}$ & $4.26 \pm 0.64^{*}$ \\
ATP/ADP & $11.5 \pm 1.0$ & & $10.3 \pm 0.4$ & $8.8 \pm 0.5^{*}$ \\
\hline
\end{tabular}

The animals were the same as those recorded in Table II. Values, expressed as millimoles/kilogram wet weight, are the means \pm SEM for 8-10 animals.

* Different from sodium acetate-injected with $P<0.05$. 


\section{TABLE $\mathrm{V}$}

Concentrations of Adenine Nucleotides, Phosphocreatine, Creatine, and Inorganic Phosphate in Brain Stem of Rats with PC Shunts.

Effect of Ammonium Acetate Injection

\begin{tabular}{|c|c|c|c|}
\hline \multirow[b]{2}{*}{ Substance } & \multirow{2}{*}{$\frac{\text { Injected with sodium acetate }}{+60 \mathrm{~min}}$} & \multicolumn{2}{|c|}{ Injected with ammonium acetate } \\
\hline & & $+10 \mathrm{~min}$ & $+60 \mathrm{~min}$ \\
\hline ATP & $2.51 \pm 0.10$ & $2.56 \pm 0.10$ & $1.92 \pm 0.11^{*}$ \\
\hline ADP & $0.22 \pm 0.02$ & $0.25 \pm 0.01$ & $0.30 \pm 0.02$ \\
\hline AMP & $0.032 \pm 0.004$ & $0.043 \pm 0.012$ & $0.070 \pm 0.014^{*}$ \\
\hline Phosphocreatine & $4.85 \pm 0.16$ & $4.49 \pm 0.12$ & $3.22 \pm 0.30^{*}$ \\
\hline Creatine & $4.94 \pm 0.26$ & $6.46 \pm 0.29^{*}$ & $6.52 \pm 0.40^{*}$ \\
\hline Inorganic phosphate & $2.61 \pm 0.19$ & $3.41 \pm 0.55$ & $4.36 \pm 0.58^{*}$ \\
\hline ATP/ADP & $11.1 \pm 1.1$ & $10.3 \pm 0.6$ & $6.8 \pm 0.8^{*}$ \\
\hline
\end{tabular}

The animals were the same as those recorded in Table II. Values, expressed as millimoles/kilogram wet weight, are the means \pm SEM for 8-10 animals.

${ }^{*}$ Different from sodium acetate-injected with $P<0.05$.

acute ammonia intoxication in normal rats depletes ATP and phosphocreatine predominantly in the basal parts of the brain.

Glycolytic and tricarboxylic acid cycle intermediates in cerebral hemispheres. Ammonia intoxication in PC rats produced substantial increases in the concentrations of all measured intermediates of the Embden-Meyerhof glycolytic pathway in the cerebral hemispheres of comatose animals $(60 \mathrm{~min}$ postinjection), and of all but glucose-6-phosphate (unchanged) in the precomatose group (Fig. 2). These changes are consistent with an ammonium ion-induced increase in cerebral glycolytic activity, as has been found to occur after acute ammonia intoxication in normal animals $(21,39)$. At both 10 and 60 min after ammonium acetate injection the increases in lactate were disproportionately greater than changes in pyruvate; the calculated lactate/pyruvate ratios were therefore consistently elevated $(33.1 \pm 2.5$ and 40.5 \pm 2.8 at 10 and $60 \mathrm{~min}$, respectively, vs. $15.8 \pm 1.9$ in controls; $P<0.01$ ).

Among the measured tricarboxylic acid cycle intermediates, $\alpha$-ketoglutarate and malate rose after ammonium acetate injection $(60 \mathrm{~min})$, whereas citrate declined (Fig. 2). Oxalacetate was calculated to have decreased. Changes in these intermediates were in the same direction at $10 \mathrm{~min}$ after ammonia loading; however, the malate rise was significant only in the comatose animals.

Amino acid concentrations in cerebral hemispheres. Ammonium ion-induced changes in amino acid concentrations of brain of shunted rats were more pronounced in the comatose animals, but some differences were apparent even during the precomatose stage
(Table VI). Thus, aspartate declined and alanine rose within $10 \mathrm{~min}$ after ammonium acetate injection, whereas concentrations of glutamate, glutamine, asparagine, and $\gamma$-aminobutyrate were unaffected. After $60 \mathrm{~min}$, aspartate levels remained depressed and asparagine increased by $20 \%$; alanine concentrations more than tripled. Glutamate fell $(-14 \%)$, despite the fact that ammonia and $\alpha$-ketoglutarate were both elevated in brain after ammonia treatment (Table II, Fig. 2). Since brain glutamine concentrations also rose by $3.5 \mathrm{mmol} / \mathrm{kg}$ (29\% above control) during this same period, the decrease in glutamate implies an accelerated conversion of glutamate into glutamine. In fact, the average rate of glutamine synthesis (calculated from the rate of accumulation of excess glutamine and, therefore, a minimal estimate) was 0.58 $\mathrm{mmol} / \mathrm{kg}$ per $\mathrm{min}$; this value is $75 \%$ higher than the rate of brain glutamine synthesis obtained in unshunted rats that were acutely intoxicated with ammonium acetate (21).

Redox state of pyridine nucleotide couples. The cytoplasmic ratio of $\left[\mathrm{NAD}^{+}\right] /[\mathrm{NADH}]$, calculated from the components of the lactic dehydrogenase equilibrium, decreased by $50 \%$ at $10 \mathrm{~min}$ after ammonium acetate injection (Table VII) and may have been further decreased after $60 \mathrm{~min}(P<0.1)$. This pattern is opposite to the changes in the $\left[\mathrm{NAD}^{+}\right] /[\mathrm{NADH}]$ ratio obtained from the components of the glutamic dehydrogenase equilibrium. The increases in $\left[\mathrm{NAD}^{+}\right] /$ [NADH] at 10 and $60 \mathrm{~min}$ after ammonium acetate injection indicate a shift toward increased oxidation within the glutamic dehydrogenase-containing compartment, thought to be principally intramitochondrial (41). The calculations indicate a dissociation between 


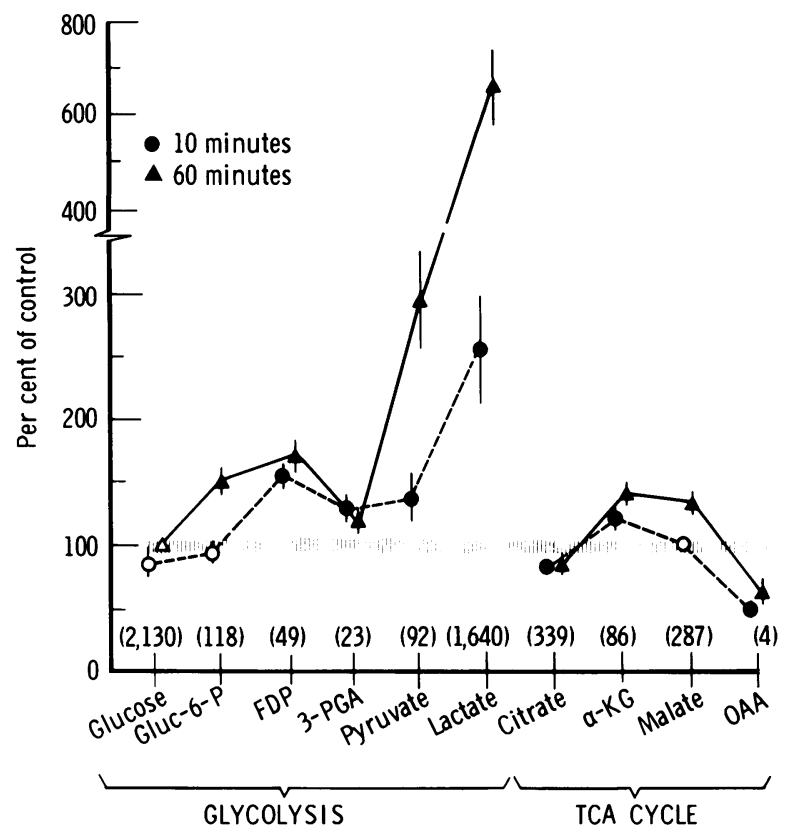

FIGURE 2 Effect of an ammonia challenge on concentrations of 10 metabolic intermediates in cerebral hemispheres of rats with PC shunts. All animals had PC shunts of 8 wk duration. Experimental animals were sacrificed at 10 or 60 min after an intraperitoneal injection of ammonium acetate $(5.2 \mathrm{mmol} / \mathrm{kg})$; the control group was sacrificed $60 \mathrm{~min}$ after an intraperitoneal injection of sodium acetate $(5.2$ $\mathrm{mmol} / \mathrm{kg}$ ). The numbers in parentheses represent mean values, expressed as $\mu \mathrm{mol} / \mathrm{kg}$ wet weight, for eight control animals; the hatched area represents \pm 1 SEM for the control population. Points denote mean values $( \pm$ SEM) for $8-10$ ammonia-treated animals. Solid symbols indicate significant differences from control $(P<0.05)$.

The concentration of oxalacetate was calculated from data for malate, pyruvate, and lactate on the assumption that the malic dehydrogenase and lactic dehydrogenase systems are in equilibrium with the same NAD pool $(27,40)$. The concentration of oxalacetate was obtained from the formula: [Oxalacetate] $=$ [Pyruvate] [Malate]/[Lactate] $\times \mathrm{K}_{\mathrm{MDH}} / \mathrm{K}_{\mathrm{LDH}}$, where $\mathrm{K}_{\mathrm{MDH}}$ and $\mathrm{K}_{\mathrm{LDH}}$ are the equilibrium constants of the malic dehydrogenase and lactic dehydrogenase reactions, respectively.

Abbreviations, Gluc-6-P, glucose-6-phosphate; FDP, fructose-1,6-diphosphate; 3-PGA, 3-phosphoglycerate; $\alpha$-KG, $\alpha$-ketoglutarate; OAA, oxalacetate; TCA cycle, tricarboxylic acid cycle.

the redox states of brain cytosol and mitochondria in chronically hyperammonemic (shunted) rats, and thus confirm and extend previous studies on normal rats subjected to acute ammonia intoxication $(19,21,42)$.

\section{DISCUSSION}

A unifying hypothesis to explain how ammonia affects brain function must take into account the variety of toxic manifestations and metabolic abnormalities caused by ammonia intoxication in normal and PC animals. Ammonia-induced coma in rats with PC shunts is associated with a fall in the cerebral metabolic rate for oxygen (36) and is thus similar to comatose conditions arising from other metabolic (hypoxia, hypoglycemia) or toxic (uremia, cirrhosis) factors (43). A critical question is whether the decline in oxygen consumption produces coma or is secondary to the decreased neuronal activity.

It seems unlikely that the early brain dysfunction caused by ammonia in PC animals is due primarily to interference with cerebral oxidative energy production. As early as $10 \mathrm{~min}$ after the ammonia challenge when the animals were already behaviorally abnormal, the concentrations of the adenine nucleotides in the brain were all within normal limits. Small but significant decreases in phosphocreatine and in the phosphocreatine/creatine ratio emerged during this precomatose stage, but such differences, in themselves, do not indicate a cerebral energy deficit. The creatine phosphokinase reaction is $\mathrm{pH}$-dependent (44), and an increase in the tissue hydrogen ion concentration, secondary to the accumulation of lactic acid (Fig. 2), could largely account for the decline in phosphocreatine (45). Admittedly, mild nitrous oxide anesthesia was employed during the biochemical studies, but this degree of anesthesia does not alter the rate of energy utilization in rat brain (cf. 46 and 47) and is unlikely to have damped the metabolic changes. In contrast to the preserved energy balance accompanying the initial stages of ammonia intoxication, PC animals did develop an abnormal cerebral energy state once superimposed ammonia intoxication produced coma. Decreased concentrations of ATP and decreased ATP/ ADP ratios were found at $1 \mathrm{~h}$ in all regions of the brain (Tables III-V). These changes occurred in the absence of generalized seizures, systemic hypoxia, or cerebral ischemia, and therefore must be related to the metabolism of ammonia. The sequence observed at 10 and 60 min thus suggests that ammonia induces a biochemical abnormality that eventually leads to a fall in ATP, perhaps at that point precipitating the irreversible brain damage that ultimately develops (35).

Cytoplasmic glycolysis provides the substrate for mitochondrial respiration via the oxidative conversion of pyruvate to citrate. The observation that pyruvate increased progressively, whereas citrate declined after ammonia loading, suggests a block at this linkage point. Inhibition of citrate formation could be mediated by low oxalacetate, concentrations of which were decreased by $50 \%$ (Fig. 2) and may have become inadequate for condensation with acetyl-coenzyme A. McKhann and Tower (18) previously observed that 15 $\mathrm{mM}$ ammonium chloride inhibited oxygen consumption and pyruvate utilization by a brain mitochondrial preparation incubated in vitro. Since added succinate failed to reverse the inhibition (by metabolically supplying oxalacetate), McKhann and Tower (18) con- 
TABLE VI

Concentrations of Some Amino Acids in Cerebral Hemispheres of Rats with PC Shunts. Effect of Ammonium Acetate Injection

\begin{tabular}{lcccc}
\hline \multirow{2}{*}{ Amino acid } & \multicolumn{2}{c}{ Injected with sodium acetate } & & \multicolumn{2}{c}{ Injected with ammonium acetate } \\
\cline { 2 - 3 } \cline { 5 - 5 } Glutamate & $9.47 \pm 0.18$ & & $9.15 \pm 0.14$ & $8.11 \pm 0.22^{*}$ \\
Glutamine & $12.0 \pm 0.7$ & & $12.3 \pm 0.6$ & $15.5 \pm 0.5^{*}$ \\
Aspartate & $2.75 \pm 0.06$ & & $1.84 \pm 0.09^{*}$ & $1.80 \pm 0.09^{*}$ \\
Asparagine & $0.101 \pm 0.003$ & & $0.099 \pm 0.007$ & $0.120 \pm 0.005 \ddagger$ \\
$\gamma$-Aminobutyrate & $1.90 \pm 0.16$ & & $1.66 \pm 0.11$ & $1.82 \pm 0.16$ \\
Alanine & $0.49 \pm 0.02$ & $0.62 \pm 0.05 \ddagger$ & $1.97 \pm 0.31^{*}$ \\
\hline
\end{tabular}

The animals were the same as those recorded in Table II. Values, expressed as millimoles/kilogram wet weight, are the means \pm SEM for 8-10 animals.

* Different from sodium acetate-injected group with $P<0.001$.

$\ddagger$ Different from sodium acetate-injected group with $P<0.02$.

cluded that the effect was not simply the result of decreased availability of oxalacetate. Whether such a block has physiological significance is not clear from the present experiments. Despite decreased citrate, other tricarboxylic acid cycle intermediates were not depleted; in fact, malate and $\alpha$-ketoglutarate were substantially elevated (Fig. 2). Moreover, ammonia treatment caused a net accumulation of $3 \mathrm{mmol} / \mathrm{kg}$ in glutamine (Table VI; $60 \mathrm{~min}$ ), presumably arising from $\alpha$-ketoglutarate via the intermediate formation of glutamate. Since glutamate decreased by only 1 $\mathrm{mmol} / \mathrm{kg}$ (Table VI), a supplementary source of carbon is needed. This is probably supplied by ammoniastimulated carbon dioxide fixation (48).
The finding that the encephalopathy of ammonia intoxication in portacaval animals precedes the development of a cerebral energy imbalance directs attention to other aspects of ammonia metabolism in searching for the biochemical lesion. In brain, the metabolism of ammonia is intimately linked with the formation and turnover of a number of amino acids, two of which, glutamic and aspartic acids, have neuroexcitatory characteristics. In precoma, aspartate was consistently decreased and with deepening coma there was a progressive rise in alanine and fall in glutamate (Table VI). Decreased glutamate is associated with reversible coma due to hypoxic hypoxia (27), hypoglycemia $(10,11)$, and hypercapnia (12),

TABLE VII

Redox States of Nicotinamide Adenine Dinucleotide Couples in Cerebral Hemispheres of Rats with PC Shunts. Effect of Ammonium Acetate Injection

\begin{tabular}{|c|c|c|c|}
\hline \multirow[b]{2}{*}{ Ratio } & \multirow{2}{*}{$\frac{\text { Injected with sodium acetate }}{+60 \mathrm{~min}}$} & \multicolumn{2}{|c|}{ Injected with ammonium acetate } \\
\hline & & $+10 \mathrm{~min}$ & $+60 \min$ \\
\hline $\begin{array}{l}\text { Cytoplasmic }\left[\mathrm{NAD}^{+}\right] /[\mathrm{NADH}] \\
\text { (lactic dehydrogenase) }\end{array}$ & $570 \pm 69$ & $272 \pm 21^{*}$ & $222 \pm 15^{*}$ \\
\hline $\begin{array}{l}\left.\text { Mitochondrial [NAD }{ }^{+}\right] /[\mathrm{NADH}] \\
\text { (glutamic dehydrogenase) }\end{array}$ & $0.93 \pm 0.17$ & $6.0 \pm 1.3^{*}$ & $12.3 \pm 2.3^{*}$ \\
\hline
\end{tabular}

The values are means $( \pm S E M)$ calculated from individual metabolite concentrations listed in Tables II and VI, and Fig. 2. Cytoplasmic and mitochondrial free [NAD $\left.{ }^{+}\right]$ [NADH] ratios were calculated from the components of the lactic dehydrogenase $\left(\left[\mathrm{NAD}^{+}\right] /[\mathrm{NADH}]=[\right.$ pyruvate $] /[$ lactate $\left.] \cdot \mathrm{K}_{\mathrm{LDH}}\right)$, and glutamic dehydrogenase $\left(\left[\mathrm{NAD}^{+}\right] /\right.$ $[\mathrm{NADH}]=[\alpha$-ketoglutarate $]\left[\mathrm{NH}_{4}{ }^{+}\right] /$[glutamate $\left.] \cdot \mathrm{K}_{\mathrm{GDH}}\right)$ reactions, where the equilibrium constants were $0.111 \mathrm{mM}$ and $3.87 \mu \mathrm{M}$, respectively (40). The pH of the tissue was held constant at 7.0.

* Different from sodium acetate-injected with $P<0.01$. 


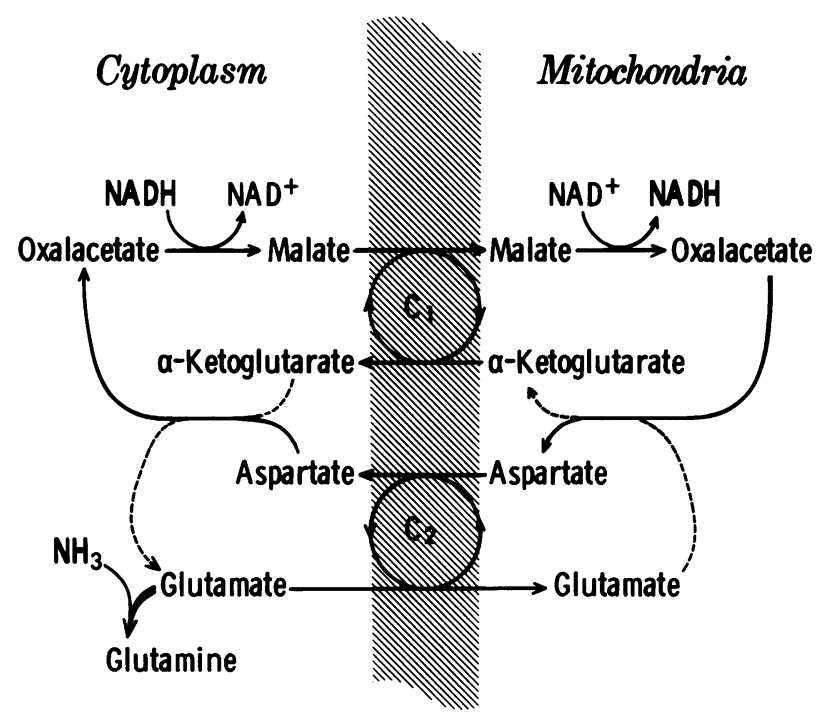

FigurE 3 Transport of reduced equivalents from cytoplasm to mitochondria via the malate-aspartate shuttle. $C_{1}$ and $C_{2}$ denote carrier systems for malate- $\alpha$-ketoglutarate and aspartate-glutamate transport, respectively. Ammonia is represented as reacting with glutamate to form glutamine in cytoplasm because glutamine synthetase of brain is predominantly extramitochondrial (53).

whereas aspartate falls in hypoxia (27) and hypercapnia (12), but rises in hypoglycemia $(10,11)$. Thus, decreases in the predominantly excitatory amino acids may play a role in the pathogenesis of ammoniainduced coma in PC animals. Rats with PC shunts are more susceptible to ammonia intoxication than sham-operated controls; the coma is prolonged and recovery is much delayed. One notable difference between normal and PC animals is that brain glutamate was $1.5 \mathrm{mmol} / \mathrm{kg}$ lower $8 \mathrm{wk}$ after portal-systemic shunting (Table I). In view of the likelihood that glutamic acid is compartmented in brain (49), this relatively small decrease in total brain glutamate (10\%) may be significant if confined to a small intracellular pool such as that involved in synaptic transmission.

Certain features of the early metabolic disturbances of ammonia intoxication also may relate to alterations in brain amino acid concentrations which, in turn, influence other major metabolic translocations in the cell. The increase in alanine and malate and the fall of aspartate and oxalacetate (Fig. 2, Table VI) are believed to result from a concerted transamination mechanism facilitated by increased pyruvate.

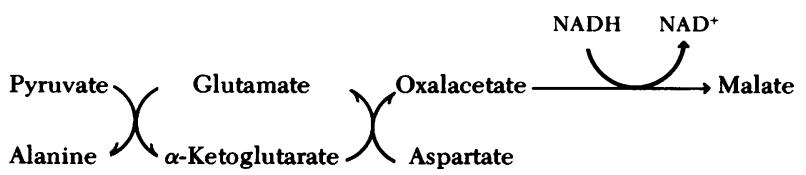

The net effect of this reaction sequence is a transamination between pyruvate and aspartate giving rise to alanine and oxalacetate. Excess pyruvate (Fig. 2), secondary to inhibition of pyruvate oxidation (see above), coupled with an elevated cytoplasmic [NADH]/ $\left[\mathrm{NAD}^{+}\right]$ratio (Table VII), would favor alanine and malate formation, as was observed. A similar metabolic response has also been found to occur in brain during coma-producing, but reversible hypoxia (27). Moreover, an elevated [NADH] $/\left[\mathrm{NAD}^{+}\right]$ratio in brain cytoplasm and an apparently decreased [NADH] $]\left[\mathrm{NAD}^{+}\right]$ ratio within the mitochondria is common to both hypoxic and ammonia-induced coma ( 9 and Table VII), suggesting that abnormal brain function in the two conditions may reflect a similar metabolic lesion, i.e., failure to transport reduced equivalents from cytoplasm to mitochondria.

Although NADH does not readily cross the mitochondrial membrane, net transfer of NADH from cytoplasm to mitochondrion does occur, presumably via an appropriate carrier system that transports reduced equivalents in lieu of NADH. In rat liver, heart, and probably, brain, reduced equivalents generated in the cytoplasm (glycolysis) are thought to be transported into the mitochondria by way of the "malate-aspartate shuttle" $(50,51)$ as described by Borst (52) (Fig. 3). The transported anions, malate, $\alpha$-ketoglutarate, aspartate, glutamate, are all significantly altered in brain by ammonia loading (Fig. 2, Table VI), glutamate, and aspartate in particular. Studies by Williamson et al. (51) with isolated heart mitochondria indicate that the rate of entry of glutamate into mitochondria is an important regulator of the malateaspartate cycle but that the affinity of the carrier system for glutamate transport is poor $\left(\mathrm{K}_{\mathrm{m}} \cong 6 \mathrm{mM}\right)$. Because such a carrier would not be saturated at normal glutamate concentrations in brain (about 11 $\mathrm{mM}$, Table I), a fall in glutamate, owing to ammoniastimulated conversion of glutamate into glutamine, and decreased aspartate after ammonia loading, may inhibit the "shuttle" or reduce its efficiency in the face of a high glycolytic flux. Such a mechanism would lead to an accumulation of NADH in the cytoplasm and could account for the more reduced state of the cytosol relative to that of the mitochondria (Table VII). Interference with hydrogen transport could also explain the delayed energy failure and reduced oxygen consumption. A deficiency of substrate (NADH) for the mitochondrial electron transport chain (the result both of failure to translocate cytoplasmically generated NADH and of the continuous removal of intramitochondrial NADH via the glutamic dehydrogenase reaction) would inhibit oxidative energy coupling and ultimately lead to a fall in ATP.

\section{ACKNOWLEDGMENT}

This investigation was supported in part by grant no. AM16739 from the U. S. Public Health Service. 


\section{REFERENCES}

1. Duffy, T. E., B. Hindfelt, and F. Plum. 1975. Effect of acute ammonia intoxication on cerebral metabolism in rats with portacaval (PC) shunts. Clin. Res. 23: 393A. (Abstr.)

2. Victor, M., R. D. Adams, and M. Cole. 1965. The acquired (non-Wilsonian) type of chronic hepatocerebral degeneration. Medicine (Baltimore). 44: 345-396.

3. Sherlock, S. 1968. Diseases of the Liver and Biliary System. F. A. Davis Company, Philadelphia, Pa. 4th Edition. 809 p.

4. Breen, K. J., and S. Schenker. 1972. Hepatic coma: present concepts of pathogenesis and therapy. In Progress in Liver Diseases. H. Popper, and F. Schnaffner, editors. Grune \& Stratton, Inc., New York. 4: 301-332.

5. Plum, F., and B. Hindfelt. 1976. The neurological complications of liver disease. In Handbook of Clinical Neurology. P. J. Vinken, and G. W. Bruyn, editors. North-Holland Publishing Company, Amsterdam. 27: 349-377.

6. Plum, F. 1971. The CSF in hepatic encephalopathy. Exp. Biol. Med. 4: 34-41.

7. Phillips, G. B., R. Schwartz, C. J. Gabuzda, Jr., and C. S. Davidson. 1952. The syndrome of impending hepatic coma in patients with cirrhosis of the liver given certain nitrogenous substances. N. Engl. J. Med. 247: 239-246.

8. McDermott, W. V., Jr., and R. D. Adams. 1954. Episodic stupor associated with an Eck fistula in the human with particular reference to the metabolism of ammonia. J. Clin. Invest. 33: 1-9.

9. Siesjö, B. K., and L. Nilsson. 1971. The influence of arterial hypoxemia upon labile phosphates and upon extracellular and intracellular lactate and pyruvate concentrations in the rat brain. Scand. J. Clin. Lab. Invest. 27: 83-96.

10. Tews, J. K., S. H. Carter, and W. E. Stone. 1965. Chemical changes in the brain during insulin hypoglycaemia and recovery. J. Neurochem. 12: 679-693.

11. Lewis, L. D., B. Ljunggren, K. Norberg, and B. K. Siesjö. 1974. Changes in carbohydrate substrates, amino acids and ammonia in the brain during insulin-induced hypoglycemia. J. Neurochem. 23: 659-671.

12. Folbergrová, J., V. MacMillan, and B. K. Siesjö. 1972. The Effect of hypercapnic acidosis upon some glycolytic and Krebs cycle-associated intermediates in the rat brain. J. Neurochem. 19: 2507-2517.

13. Kazemi, H., N. S. Shore, V. E. Shih, and D. C. Shannon. 1973. Brain organic buffers in respiratory acidosis and alkalosis. J. Appl. Physiol. 34: 478-482.

14. Thorn, W., and J. Heimann. 1958. The effects of anoxia, ischaemia, asphyxia and reduced temperature on the ammonia level in the brain and other organs. J. Neurochem. 2: 166-177.

15. Ljunggren, B., H. Schutz, and B. K. Siesjö. 1974. Changes in energy state and acid-base parameters of the rat brain during complete compression ischemia. Brain. Res. 73: 277-289.

16. Tews, J. K., and W. E. Stone. 1965. Free amino acids and related compounds in brain and other tissues: Effects of convulsant drugs. Prog. Brain Res. 16: 135163.

17. Shaw, R. K., and J. D. Heine. 1965. Effect of insulin on nitrogenous constituents of rat brain. J. Neurochem. 12: $527-532$.

18. McKhann, G. M., and D. B. Tower. 1961. Ammonia toxicity and cerebral oxidative metabolism. Am. J. Physiol. 200: 420-424.

19. Schenker, S., D. W. McCandless, E. Brophy, and M. S.
Lewis. 1967. Studies on the intracerebral toxicity of ammonia. J. Clin. Invest. 46: 838-848.

20. Hindfelt, B., and B. K. Siesjö. 1971. Cerebral effects of acute ammonia intoxication. II. The effect upon energy metabolism. Scand. J. Clin. Lab. Invest. 28: 365-374.

21. Hawkins, R. A., A. L. Miller, R. C. Neilsen, and R. L. Veech. 1973. The acute action of ammonia on rat brain metabolism in vivo. Biochem. J. 134: 1001-1008.

22. Lee, S. H., and B. Fisher. 1961. Portacaval shunt in the rat. Surgery (St. Louis). 50: 668-672.

23. Holmin, T., and B. K. Siesjö. 1974. The effect of portacaval anastomosis upon the energy state and upon acidbase parameters of the rat brain. J. Neurochem. 22: 403-412.

24. Nelson, S. R., D. W. Schulz, J. V. Passonneau, and O. H. Lowry. 1968. Control of glycogen levels in brain. J. Neurochem. 15: 1271-1279.

25. Folbergrová, J., J. V. Passonneau, O. H. Lowry, and D. W. Schulz. 1969. Glycogen, ammonia and related metabolites in the brain during seizures evoked by methionine sulphoximine. J. Neurochem. 16: 191-203.

26. Vannucci, R. C., and T. E. Duffy. 1974. Influence of birth on carbohydrate and energy metabolism in rat brain. Am. J. Physiol. 226: 933-940.

27. Duffy, T. E., S. R. Nelson, and O. H. Lowry. 1972. Cerebral carbohydrate metabolism during acute hypoxia and recovery. J. Neurochem. 19: 959-977.

28. Vergara, F., F. Plum, and T. E. Duffy. 1974. $\alpha$-Ketoglutaramate: Increased concentrations in the cerebrospinal fluid of patients in hepatic coma. Science (Wash. D. C.). 183: 81-83.

29. Lowry, O. H., and J. V. Passonneau. 1972. A Flexible System of Enzymatic Analysis. Academic Press, Inc., New York. 146-218.

30. Bergmeyer, H. U., E. Bernt, H. Möllering, and G. Pfleiderer. 1974. L-Aspartate and L-Asparagine. In Methods of Enzymatic Analysis. H. U. Bergmeyer, editor. Academic Press, Inc., New York. 4: 1696-1700.

31. Meister, A. 1954. Studies on the mechanism and specificity of the glutamine- $\alpha$-keto acid transamination-deamidation reaction. J. Biol. Chem. 210: 17-35.

32. Jakoby, W. B., and E. M. Scott. 1959. Aldehyde oxidation. III. Succinic semialdehyde dehydrogenase. J. Biol. Chem. 234: 937-940.

33. Mann, J. D., J. L. Bollman, K. A. Huizenga, T. Farrar, and J. H. Grindlay. 1954. Blood ammonia, experimental and clinical study in abnormalities of the liver and portal circulation. Gastroenterology. 27: 399-410.

34. Kyu, M. H., and J. B. Cavanagh. 1970. Some effects of porto-caval anastomosis in the male rat. Br. J. Exp. Pathol. 51: 217-227.

35. Cavanagh, J. B. 1974. Liver bypass and the glia. Res. Publ. Assoc. Res. Nerv. Ment. Dis. 53: 13-38.

36. Gjedde, A., A. Lockwood, T. E. Duffy, and F. Plum. 1976. Effect of ammonia on cerebral metabolism of rats with portacaval shunts. Trans. Am. Neurol. Assoc. 101: 180181.

37. Hindfelt, B., and B. K. Siesjö. 1971. Cerebral effects of acute ammonia intoxication. I. The influence on intracellular and extracellular acid-base parameters. Scand. J. Clin. Lab. Invest. 28: 353-364.

38. Hindfelt, B. 1972. The effect of sustained hyperammonemia upon the metabolic state of the brain. Scand. J. Clin. Lab. Invest. 30: 245-255.

39. James, I. M., L. MacDonnell, and C. Xanalatos. 1974. Effect of ammonium salts on brain metabolism. J. Neu rol. Neurosurg. Psychiatry. 37: 948-953.

40. Williamson, D. H., P. Lund, and H. A. Krebs. 1967. The redox state of free nicotinamide-adenine dinucleo- 
tide in the cytoplasm and mitochondria of rat liver. Biochem. J. 103: 514-527.

41. Miller, A. L., R. A. Hawkins, and R. L. Veech. 1973. The mitochondrial redox state of rat brain. J. Neurochem. 20: $1393-1400$.

42. Worcel, A., and M. Erecinska. 1962. Mechanism of inhibitory action of ammonia on the respiration of ratliver mitochondria. Biochim. Biophys. Acta. 65: 27-33.

43. Lassen, N. A. 1959. Cerebral blood flow and oxygen consumption in man. Physiol. Rev. 39: 183-238.

44. Kuby, S. A., and E. A. Noltmann. 1962. ATP-Creatine transphosphorylase. In The Enzymes. P. D. Boyer, H. Lardy, and K. Myrbäck, editors. Academic Press, Inc., New York. 2nd edition. 6: 515-603.

45. Siesjö, B. K., J. Folbergrová, and V. MacMillan. 1972. The effect of hypercapnia upon intracellular $\mathrm{pH}$ in the brain, evaluated by the bicarbonate-carbonic acid method and from the creatine phosphokinase equilibrium. J. Neurochem. 19: 2483-2495.

46. Swaab, D. F., and K. Boer. 1972. The presence of biologically labile compounds during ischemia and their relationship to the EEG in rat cerebral cortex and hypothalamus. J. Neurochem. 19: 2843-2853.

47. Nilsson, B., K. Norberg, C.-H. Nordström, and B. K. Siesjö. 1975. Rate of energy utilization in the cerebral cortex of rats. Acta Physiol. Scand. 93: 569-571.
48. Berl, S. 1971. Cerebral amino acid metabolism in hepatic coma. Exp. Biol. Med. 4: 71-84.

49. Berl, S., and D. D. Clarke. 1969. Compartmentation of amino acid metabolism. In Handbook of Neurochemistry. A. Lajtha, editor. Plenum Publishing Corporation, New York. 2: 447-472.

50. Williamson, J. R., A. Jakob, and C. Refino. 1971. Control of the removal of reducing equivalents from the cytosol in perfused rat liver. J. Biol. Chem. 246: $7632-7641$.

51. Williamson, J. R., B. Safer, K. F. LaNoue, C. M. Smith, and E. Walajtys. 1973. Mitochondrial-cytosolic interactions in cardiac tissue: Role of the malate-aspartate cycle in the removal of glycolytic NADH from the cytosol. In Rate Control of Biological Processes D. D. Davies, editor. Cambridge University Press, New York. 241281.

52. Borst, P. 1963. Hydrogen transport and transport metabolites. In Funktionelle und Morphologische Organisation der Zelle. P. Karlson, editor. Springer-Verlag Kg, Berlin. 137- 162.

53. Sellinger, O. Z., and F. de Balbian Verster. 1962. Glutamine synthetase of rat cerebral cortex: Intracellular distribution and structural latency. J. Biol. Chem. 237: 28362844. 